\title{
Safety settings in equestrian facilities
}

\author{
A. Checchi, ${ }^{1}$ S. Casazza² \\ 'University of Bologna, Dept. of Agri-Food Science and Technology, Bologna, Italy; \\ ${ }^{2}$ Expert professional for safety in working environments, ASH srls, Brugherio (MB), Italy
}

\begin{abstract}
In recent years an increased attention has been paid to the risks that can emerge within the equestrian environment. In fact, the activities that are carried out every day, whether of working or sport nature, can cause serious traumatic events. The main problems are related to the following risks: biological and physical contact, followed by chemical, electrical, mechanical risks that are common to also a lot of other situations. All these specific risks, of which we talk about in this work, can be contained through proper training and information of workers. The likelihood of accidents can be reduced also applying appropriate behavioural requirements and certain quality and construction parameters used in structures. Inside the equestrian facilities all the main safety systems should be well indicated, also through appropriate signs.
\end{abstract}

\section{Introduction}

Analysis and definition of risks involves great difficulties due to the presence of horses both in permanent structures, that in an unknown environments such as a sport or show events. Safety rules should always be known to all the operators and put into effect in every phase of any activity that has an interaction between man and horse or horses' dedicated structures and should be respected, in every least detail, during the carrying out of any procedure. Beyond this, it is very important to check out the construction characteristics of the entire stable, laying on eye on dimensions of stalls, doors, passages and every place where a horse will transit along with a person on his side. All kinds of plants, installations and machineries, such as treadmills, drying lamps and so on, must strictly respond to the rules and be maintained in perfect conditions of use and each worker must know how to use them correctly.

Correspondence: A. Checchi, University of Bologna, Dept. of Agri-Food Science and Technology, Viale Fanin, 50, Bologna, Italy.

Tel. +39.051.2096101 - Fax: +39.051.2096171.

E-mail: antonio.checchi@unibo.it

Key words: horse, risks, prevention.

CC Copyright A. Checchi and S. Casazza, 2013

Licensee PAGEPress, Italy

Journal of Agricultural Engineering 2013; XLIV(s2):e153

doi:10.4081/jae.2013.s2.e153

This article is distributed under the terms of the Creative Commons Attribution Noncommercial License (by-nc 3.0) which permits any noncommercial use, distribution, and reproduction in any medium, provided the original author(s) and source are credited.

\section{Methods}

\section{The risk from physical contact with the horse}

Among those who work around a horse, many, but not all, know that all his behaviours are intrinsically and instinctively aimed at the search for pleasure or to avoid pain and suffering, which can also be identified in the intolerance with respect to a person or a situation. However operators do not always consider the effect that the instinct has on the perception of these sensations: sometimes the stress caused by the frustration of instincts can be worse than the pain itself for a horse.

The stress state is of such importance in the horse that its presence is detected also by the increase in blood levels of cortisol and catecholamines. Consequently, an important equestrian safety parameter consists in understanding the instincts of the horse and acting so to create less emotional conflicts possible. Forcing the horse to do something against his will, is equivalent to significantly increase his level of emotional stress and to make him react in an unpredictable and dangerous manner.

This premise wants to indicate of the most frequent and harmful physical agent investigated: the aggressive action of the horse, which is manifested by kicking, biting and crushing with his limbs or body.

Evaluating the percentage of trauma occurring in equestrian activities, it has been shown that these activities are having one of the highest risk percentage of traumatic events among all sports, including motorcycling and motoring.

The most frequent causes of injuries are falls from the horse, the crushing from the horse, bites and kicks. The majority of serious and fatal injuries consists of head injuries that could have been less severe if the rider had worn properly a specific helmet. Even the use of shoes or boots with reinforced tips could prevent a good part of traumatic events or otherwise reduce their severity.

The obvious conclusion from what above is that the equestrian injuries are a serious health problem (still undervalued), which deserves a focused commitment to prevention, in each category of workers affected, by stressing the importance, for preventive purposes, of training the personnel in order to raise awareness of the correct perception of the risk, the use of personal protective equipment and the use of appropriate procedures.

\section{The biological risk}

There is talk of biological risk to human health in relation to exposure to organisms and pathogenic microorganisms or not, animals and human endoparasites, which may be present in the workplace.

The biological agent is any organism, even genetically modified, ecto-and endoparasites, of animal or human origin, being capable of causing infection, allergy or poisoning. According to the Legislative Decree 81/2008, biological agents are classified into specific classes according to the degree of danger.

This type of risk assumes a high importance in our context, thus diversifying this type of activity from those that, even if in the presence of animals, do not provide for such a close and ongoing relation- 
ship with them and claiming, in this case, greater attention measures to be put in place.

The biological risk consists, on the one hand, in the danger that a disease of the horse can be transmitted to humans, generating in them a pathology similar for the etiological agent and often also for symptoms: in this case we speak about zoonoses.

Zoonoses can spread from animal to animal and from animals to humans and, usually, are not transmitted from man to man. Therefore a man gets sick only by contact with animal fluids or breath.

The assessment of this type of risk must be done in collaboration with the company physician, which must have a deep knowledge of diseases communicable to humans that can affect the horses with whom operators work and the related clinical manifestations in man himself. There must be a well-established and constant synergy between the Physician, the Responsible for the Service of Prevention and Protection and the Veterinarian who knows the health status of the stable in order to monitor the situation and immediately implement measures of organizational, technical and procedural to prevent transmission.

In this contest, a great relevance is given by the use of personal protective equipment, such as masks and goggles and work gloves.

Preventive and periodic visits must be carried out for the operators in the sector, which determines that do not exist conditions of particular sensitivity to infections, and to which a program of vaccine prophylaxis will follow along with the constant monitoring of the effectiveness of protection measures applied.

Another risk factor of great importance is the dust in stables, made up of particles that are derived from fodder, from litter trays, hair of horses and drying of manure. Workers subject to risk are those who have prolonged contact with animals and that manipulate bedding and feed. The danger of dust is due to the ability to carry pathogens, as well as animal and plant particles with allergenic effect, at the level of the respiratory system (eg, fungal spores). It is mainly the spores of fungi (mushrooms) and thermophilic actinomycetes, which originate from the hay and straw poorly preserved, the main cause of the onset of lung diseases such as eg. bronchial asthma, chronic bronchitis and a common disease known as farmer's lung.

In addition, the horse dander, dust mites, hair, saliva, droppings and debris from plant foods can cause allergic respiratory diseases, lung disease or pneumonia awareness, as well as chronic bronchitis. The same applies to environmental allergens such as pollens, richly present in the rural environment where this type of work is done.

To avoid as much as possible the exposure to various environmental pollutants, it is necessary to regularly use masks, in particular during the cleaning operations: it should be noted that the higher concentration of the different pollutants is revealed precisely in conjunction with these operations.

\section{Outside housing}

All animals must be kept in proper housing conditions which must follow the rules described below:

- minimal surfaces are defined by the height at the withers;

- the stall must be designed so that horses can lie down, rest and rise appropriately and beddings must be dry, abundant, free from dust and always kept clean;

- floors should not be slippery or dry;

- there must be provided in the paddock a rest area clean, dry, soft, which allows the horses to remain lying down for long times;

- in the stables where the horses are kept in groups, the lower-ranking animals must be able to avoid those of higher rank;

- horses kept permanently outdoors should have a place to find a protected shelter from strong winds, heavy rainfall and, taking advantage of the shadow, as a protection against flies,
- external soils must not be slippery and the mud must not exceed the crown of the foot,

- shelters must be easily accessible and spacious so that animals can lie down and get up normally, must be constructed in such a way that there is no risk of injury.

\section{Working on walkers and treadmills}

While bringing the horses to work within a walker or on a treadmill, the following procedures must be observed with attention.

The walker must always be completely stopped before opening the door to let the horse in. Once inside, you will reassure the horse and take off the halter. After closing the door, you can restart the walker, first at a moderate speed and then adjusted to the desired speed. At this point, it'a a good habit to follow the trend for some moment, keeping an eye on the attitude of the horse just introduced and on the other horses already present, and only after verifying that their attitude is quiet, it's possible to leave them alone, without ever leaving the situation totally uncontrolled.

More attention should be paid when placing horses on a treadmill, especially if the horse is not used to this type of equipment and movement. In fact, the walker is "down to earth" while the treadmill is on a structure slightly raised off the ground, which can also be adjusted with a variable inclination and the horse is moving alone, not in company of other horses that may calm him. It is therefore suggested to perform this operation with the presence of two operators, at least until the horse has acquired a familiarity with the equipment and the situation. With the treadmill turned off, you drive up the horse and then block the back side with the appropriate bar that is placed behind the horse's croup and the front side with a bar at chest level. Usually two lungs or chains with a safety release system for cases of emergency are used to tie the horse by the halter. Once set the treadmill in motion and settled the speed and time of training, the horse can be left to walk by himself, without being distracted or disturbed by external elements. The safety system of treadmills provides that if the horse bumps abruptly against the rear or front bar, the whole system stops and the front bar is unlocked. If the horse is not in difficulty he will remain stationary, tied on the platform, but in case of panic, the tie will break allowing him to get off the treadmill. Despite this safety system, the horse should never be left completely unattended during this workout and the treadmill should be located in a secluded and segregated place so that the horse cannot run away scared.

\section{Grooming operations}

The term "grooming" regards all the operations of cleaning and tidying of a horse performed in everyday life with which you shall keep clean the horse according to good standards of hygiene.

Wild horses are able to take care of themselves, of their skin and their mantle, but if domesticated and in captivity, they lose this instinct and man has to provide for them. It is important that at least once a day, in housed horses, all the cleaning operations are executed taking care of every single anatomic part, regardless of the use of the equine.

Thanks to the grooming operations is also possible to monitor the general conditions and preserve the horse from many diseases, both internal and external, because it turns out to be a thorough inspection of the body of the animal with the result of constant monitoring.

This kind of activity that places man in a very close contact with horses is definitely, of all the operations, the most risky, but cannot be avoided: nevertheless if approached with caution, attention, in proper operating conditions and supported by proper training, the residual risk can be reduced to an acceptable level.

The risks that operators may encounter during grooming are indeed many, from simple stepping on a foot, to small bites, up to the crushing of body and feet. 
The intensity of the risk varies depending on the difficulty and the character of the horses with whom you have to deal: we must therefore pay close attention to every little gesture and the way in which it is accomplished. Keep in mind that a calm and reassuring voice predisposes the horse to a positive attitude towards the person who takes care of him: always takes advantage of this tool.

The grooming operations should always take place in "safe" areas, such as dedicated spaces inside the stables and never inside the stall.

It can happen that the horse identifies the stall as his home and may trigger in him an attitude of ownership and protection towards all those who access it. This aspect produces nervousness and does not allow man to be able to have confidence. Also, inside the stall, the necessary supports for tools are lacking and it is difficult to perform a correct and deep cleansing of the body (especially in the lower limbs) due to the presence of litter and dust, but especially this situation does not allow a convenient and ready escape.

The service areas should contain all the equipment needed to carry out these operations and the position of the working tools should be conceived to favour the ergonomics of the working phases and operator. These places must be kept clean and tidy and we recommend the reorganization after the passage of each horse. They should also be equipped with good lighting and escape routes.

You should pay particular attention to bring the tools near the body of the horse with kindness, in such a way that he will not be afraid, just as it would be good, before working in the lower parts of the body, that the horse perceives the presence of man and his intention.

The operator's concentration must remain always high and abrupt movements are not allowed.

Inside the service areas the horse should be tied "to the two winds", to avoid that he can turn abruptly and be kept as still as possible. It is also true, however, that certain horses, especially young ones, are very nervous when they feel immobilized and bounded, and so they start to pull on the lunge, with the risk of tipping, slipping, of injury in various ways and injuring the operator. With these subjects a balance must be seeken between the operator's safety and the horse's tranquillity, gradually getting them used to being tied, leaving them attached just to one side of the halter, in a confined place, with a loose lead rope and if necessary with the assistance of a second person. With patience and attention, even these difficult subjects can be made more tolerant to the situation.

After working, the horse must be taken back in his stall, he must proceed slowly and behind the man who, once inside, will have to move over to let the horse enter completely and then prepare to exit, releasing first the halter and closing the door behind him.
It is important that during this final operation man and horse never give each other the shoulders, and that, while the operator exits the stall, also the horse stands with his head turned towards the entrance.

\section{Expected Results}

Analyzing the procedures aims to encode and teach management habits for every worker, in order to protect their life and safety during the contact with horses and at the same time to assure to the stable good operating conditions and productivity that will make it competitive towards other stables in which the fundamental safety concepts are lacking. A working activity based on safety of structures, plants and procedures and on the application of rules of prevention surely brings to the appeasement of operators involved, which will be able to operate in greater serenity conditions.

\section{Bibliography}

Bozzi S., V. Bracaloni, Cialdella M.L. (2005), Handbook of safety in equine practice, University of Pisa

Checchi, S. Casazza - Guidelines towards an optimization of safety factors in equestrian shows - XXXIII CIOSTA conference

De Maria L. (1989) - The Big Book of the horse - De Agostini Geographic Institute

De Maria V. (2002), Horse and rider, Demeter

Di Pede, L. Vivaldi, M. Sabatini - Safety Manual in the horse industry Azienda USL 5 Tuscany Pisa

DIPROVAL - Work safety in animal husbandry - Faculty of Agriculture, University of Bologna

Ministry of Health (2011), The Ministry of Health for the horse Standards, rules and protection projects

Ministry of Health (2011), The sensory world of the horse

UFV-Federal Veterinary Office (2003), Horses: how to handle them

FVO - Federal Veterinary Office (2009), Requirements for the exit of horses

FVO - Federal Veterinary Office - (2011), Horses - I take care of my pet

Zorzan C. (2009), The Manual of the Horse - Breeds and choice. Psychology. Power. First Aid, Giunti Publishing. 